\title{
Influência das condições de processo na cinética de hidrólise enzimática de carne de frango
}

\author{
Influence of process conditions on enzymatic hydrolysis kinetics of chicken meat
}

Louise Emy KUROZAWA ${ }^{1}$, Kil Jin PARK², Miriam Dupas HUBINGER ${ }^{1 \star}$

\begin{abstract}
Resumo
A influência da temperatura, $\mathrm{pH}$ e razão enzima:substrato na cinética de hidrólise enzimática de carne de frango utilizando a protease Alcalase ${ }^{\circledR}$ 2,4 L foi avaliada neste trabalho. Os experimentos foram conduzidos à temperatura de 43 a $77^{\circ} \mathrm{C}$, razão enzima:substrato de 0,8 a 4,2\% p/p e pH de 7,16 a 8,84, de acordo com um planejamento experimental completo, totalizando 17 ensaios. A reação foi monitorada, utilizando-se o método $\mathrm{pH}$-stat para obtenção dos graus de hidrólise em função do tempo de processo. As curvas de hidrólise obtidas apresentaram uma alta taxa inicial de reação, seguida da sua diminuição até alcançar uma fase estacionária. Os resultados experimentais da cinética de reação foram ajustados a um modelo empírico, que consiste na variação do grau de hidrólise em função do logaritmo neperiano do tempo. Esse modelo apresentou um bom ajuste, com coeficientes de determinação superior a 0,96 e desvio relativo médio inferior a $10 \%$. Os parâmetros do modelo foram avaliados através de um planejamento experimental, de modo a verificar a influência das variáveis de reação sobre eles. O aumento da razão enzima:substrato e da temperatura acarretou maiores valores do parâmetro $a$. O parâmetro $b$ não sofreu influência da variável razão enzima:substrato e o seu valor aumentou com o aumento da temperatura. A variável pH afetou significativamente os parâmetros estudados.
\end{abstract}

Palavras-chave: proteína; $p H$-stat; modelagem; planejamento experimental.

\begin{abstract}
The hydrolysis of chicken breast meat by commercial protease Alcalase ${ }^{\circledR} .4 \mathrm{~L}$ was studied in order to evaluate the temperature, renzyme:substrate ratio, and $\mathrm{pH}$ influence on enzymatic hydrolysis kinetics. The tests were carried out under different conditions with respect to temperature $\left(43-77^{\circ} \mathrm{C}\right)$, enzyme:substrate ratio $\left(0.8-4.2 \% \mathrm{w} / \mathrm{w}\right.$, g enzyme/100 g protein), and $\mathrm{pH}(7.16-8.84)$ according to factorial $2^{3}$ experimental design with the total of 17 tests. The reaction was monitored by the $\mathrm{pH}$-stat method to obtain the degree of hydrolysis values at different intervals of time. The hydrolysis curves were characterized by high initial reaction rates followed by decreases in the reaction rate up to the stationary phase. The results were fitted an exponential model that presented a good fit with high determination coefficient and low average relative error. The variables influence on model parameters was observed by experimental design. An increase in the enzyme:substrate ratio and temperature led to higher parameter a values. The parameter $b$ was not affected by the enzyme:substrate ratio and its value increased with higher temperature. The variable $\mathrm{pH}$ affected significantly the parameters $a$ and $b$.

Keywords: protein; $\mathrm{pH}$-stat; modeling; experimental design.
\end{abstract}

\section{Introdução}

O processo de hidrólise proteica consiste na clivagem química ou enzimática de moléculas de proteínas em pequenos peptídeos de tamanhos diversos e, eventualmente, em aminoácidos. Os hidrolisados proteicos podem ser obtidos basicamente através da hidrólise química ou enzimática (ADLER-NISSEN, 1985).

$\mathrm{Na}$ hidrólise enzimática, enzimas proteolíticas são empregadas para solubilizar a proteína do alimento, resultando na separação de duas frações: uma insolúvel, geralmente utilizada em ração animal; e uma solúvel, que contém a proteína hidrolisada e um baixo teor de lipídios. A proteína hidrolisada pode ser convertida em ingrediente a ser incorporado em alimentos processados, como um realçador de sabor, ingrediente funcional ou um suplemento para alimentos com baixa qualidade proteica ou para fórmulas balanceadas para atletas ou indivíduos que não podem digerir a proteína intacta (FURLAN; OETTERER, 2002; SGARBIERI, 1996). Desta forma, a disponibilidade de produtos nutricionalmente equilibrados, utilizando hidrolisados proteicos, pode fornecer importante aporte proteico em dietas alimentares.

A carne de peito de frango possui uma composição homogênea, um alto conteúdo de proteína $(22 \mathrm{~g} / 100 \mathrm{~g}$ carne) e um baixo teor de lipídios ( $3 \mathrm{~g} / 100 \mathrm{~g}$ carne) quando comparada com outros cortes da ave, tais como a asa (18 g de proteína ou lipídio/100 g carne) e coxa (18 g proteína ou $5 \mathrm{~g}$ lipídios/100 g carne). Além disso, as proteínas de origem animal são as mais completas por apresentarem um perfeito equilíbrio de aminoácidos essenciais, isto é, aqueles que o

Recebido para publicação em 13/11/2007

Aceito para publicação em 3/7/2008 (003016)

${ }^{1}$ Faculdade de Engenharia de Alimentos, Universidade Estadual de Campinas - UNICAMP, CP 6121, CEP 13083-970, Campinas - SP, Brasil, E-mail: mhub@fea.unicamp.br

2 Faculdade de Engenharia Agrícola, Universidade Estadual de Campinas - UNICAMP

${ }^{*}$ A quem a correspondência deve ser enviada 
corpo humano não sintetiza a partir dos demais e que, por isso, devem estar presentes nos alimentos ingeridos (FELíCIO, 2006; TACO, 2004).

Devido à baixa rentabilidade dos produtos in natura, atualmente observa-se uma estratégia de diferenciação de produtos avícolas pelas grandes empresas do setor. Estas têm dado ênfase aos produtos de maior valor agregado, buscandose, desta forma, proteção contra as oscilações no mercado de commodities e maior rentabilidade (MATIAS; MEIRELLES; CALDEIRA, 2006). A obtenção de hidrolisados proteicos de carne de frango pode representar uma alternativa para o setor.

A hidrólise enzimática é muito estudada para diversos tipos de fontes proteicas, tais como catla, vísceras de carneiro, carpacapim, molusco, concentrado proteico de peixe, salmão, isolado proteico de soja e caseína bovina (BHASKAR et al., 2007a; BHASKAR et al., 2007b; WASSWA et al., 2007; XIA; WANG; XU, 2007; NILSANG et al., 2005; SATHIVEL et al., 2005; MARTINS, 2005; ROMAN; SGARBIERI, 2005). Entretanto, para a carne de frango, esse processo é muito pouco descrito na literatura, representando, no entanto, uma etapa importante para a indústria de rações, que atualmente realiza a hidrólise de miúdos, descarte ou carne mecanicamente separada, de acordo com protocolos vindos das matrizes internacionais da empresa, com muito poucos dados publicados sobre os rendimentos e a cinética da etapa de hidrólise.

O controle das condições de hidrólise enzimática e a escolha adequada da enzima permitem a obtenção de produtos com características adequadas a uma dada aplicação na formulação de alimentos.

De acordo com Adler-Nissen (1985), as variáveis mais importantes em uma reação enzimática são: concentração e especificidade da enzima, temperatura e $\mathrm{pH}$ da reação, e a natureza do substrato. O conhecimento desses fatores é importante, uma vez que a otimização dos parâmetros da hidrólise enzimática da carne é essencial para desenvolver um processo ótimo e econômico.

A metodologia de superfície de resposta é uma técnica que tem sido aplicada com sucesso na otimização de processos alimentícios e consiste de um grupo de procedimentos matemáticos e estatísticos para estudar a influência de diversos fatores (variáveis independentes) sobre uma ou mais respostas (variáveis dependentes). Esta metodologia gera uma correlação matemática capaz de descrever o processo em estudo (BARROS NETO; SCARMINIO; BRUNS, 1996; RODRIGUES; IEMMA, 2005).

Dessa forma, o objetivo do trabalho foi avaliar a influência das condições de processo (temperatura, $\mathrm{pH}$ e razão enzima:substrato) na cinética de hidrólise enzimática de carne de frango (corte de peito), utilizando a enzima Alcalase $^{\infty}$ da empresa Novozymes (Bagsvaerd, Dinamarca).

\section{Material e métodos}

\subsection{Material}

Para a realização desse trabalho, foram utilizados peitos de frango fornecidos congelados pela Doux Frangosul S.A (Montenegro, RS, Brasil). A composição centesimal da carne foi obtida de acordo com a AOAC (1997). Para o processo de hidrólise enzimática da carne, foi utilizada a protease Alcalase $^{\bullet}$ da empresa Novozymes (Bagsvaerd, Dinamarca), com atividade declarada de 2,4 AU/g.

\subsection{Hidrólise enzimática}

Para a preparação das amostras para a hidrólise enzimática, o peito de frango foi descongelado durante a noite anterior; tendões, nervos, pele e gordura visível foram retirados; e então a carne foi moída em um homogeneizador e diluída em água destilada (proporção carne:água de 1:3 p/p). A mistura foi transferida para um béquer encamisado, sendo agitada por um agitador magnético, aquecida para uma dada temperatura e o pH ajustado com solução de $\mathrm{NaOH} 2 \mathrm{~N}$. Em seguida, a enzima foi adicionada e a reação monitorada, utilizando-se o método pH-stat, titulando-se continuamente $\mathrm{NaOH} 2 \mathrm{~N}$, de modo a manter o pH constante. Para o cálculo do grau de hidrólise, o conteúdo de base consumida foi anotado em intervalos de 5 minutos na primeira hora, 10 minutos da segunda hora, 15 minutos para as duas horas seguintes e 30 minutos até que as variações do consumo da base fossem insignificantes. Os ensaios experimentais foram conduzidos em temperaturas variando de 43 a $77^{\circ} \mathrm{C}$, razão enzima:substrato de 0,8 a $4,2 \%$ p/p, e pH de 7,16 a 8,84 conforme Tabela 1 do planejamento experimental, apresentada na seção 3.5. Finalizada a reação, a enzima foi

Tabela 1. Ensaios para o planejamento experimental, variando os parâmetros temperatura $(T)$, razão enzima:substrato $(E / S)$ e pH nos experimentos.

\begin{tabular}{ccccccc}
\hline Ensaio & \multicolumn{5}{c}{ Variáveis Independentes } \\
\cline { 2 - 7 } & \multicolumn{5}{c}{ Real } & $\mathrm{T}$ Codificado \\
\cline { 2 - 7 } & $\mathrm{T}\left({ }^{\circ} \mathrm{C}\right)$ & $\mathrm{E} / \mathrm{S}(\%)$ & $\mathrm{T}$ & $\mathrm{pH}$ \\
\hline 1 & 50 & 1,5 & 7,5 & -1 & -1 & -1 \\
2 & 70 & 1,5 & 7,5 & 1 & -1 & -1 \\
3 & 50 & 3,5 & 7,5 & -1 & 1 & -1 \\
4 & 70 & 3,5 & 7,5 & 1 & 1 & -1 \\
5 & 50 & 1,5 & 8,5 & -1 & -1 & 1 \\
6 & 70 & 1,5 & 8,5 & 1 & -1 & 1 \\
7 & 50 & 3,5 & 8,5 & -1 & 1 & 1 \\
8 & 70 & 3,5 & 8,5 & 1 & 1 & 1 \\
9 & 43 & 2,5 & 8 & $-1,68$ & 0 & 0 \\
10 & 77 & 2,5 & 8 & 1,68 & 0 & 0 \\
11 & 60 & 0,8 & 8 & 0 & $-1,68$ & 0 \\
12 & 60 & 4,2 & 8 & 0 & 1,68 & 0 \\
13 & 60 & 2,5 & 7,16 & 0 & 0 & $-1,68$ \\
14 & 60 & 2,5 & 8,84 & 0 & 0 & 1,68 \\
15 & 60 & 2,5 & 8 & 0 & 0 & 0 \\
16 & 60 & 2,5 & 8 & 0 & 0 & 0 \\
17 & 60 & 2,5 & 8 & 0 & 0 & 0 \\
\hline
\end{tabular}


inativada por aquecimento da mistura $\left(85^{\circ} \mathrm{C} / 10\right.$ minutos), seguida de resfriamento em temperatura ambiente. A mistura foi centrifugada (modelo Allegra 25R, fabricante Beckman Coulter, Fullerton, EUA) a $3500 \mathrm{rpm}$ por 20 minutos para separar o resíduo, com lipídios e material que não foi hidrolisado (DINIZ; MARTIN, 1997), do sobrenadante, contendo o hidrolisado proteico.

\subsection{Determinação do grau de hidrólise}

$\mathrm{O}$ processo de hidrólise pode ser medido através da determinação do grau de hidrólise $(G H)$, que pode ser obtido pelo método $\mathrm{pH}$-stat ou método de titulação de grupos $\alpha$-amino liberados em $\mathrm{pH}$ e temperatura constantes (ADLERNISSEN, 1985).

O grau de hidrólise foi definido por ADLER-NISSEN (1985) como sendo o número de ligações peptídicas hidrolisadas, expresso em equivalentes de hidrólise $(h)$, em relação ao número total de ligações peptídicas antes da reação $\left(h_{\text {total }}\right)$. Para a maioria das proteínas, $h_{\text {total }}$ corresponde a 8 moles equiv $/ \mathrm{kg}$ de proteína, estimado com base na composição de aminoácidos. No caso de proteínas de carne, o valor é 7,6 moles equiv/ kg de proteína, que foi utilizado no cálculo do valor de $G H$ (Equação 1).

$G H(\%)=\frac{h}{h_{\text {total }}} \times 100=\frac{B \times N_{b}}{M P \times \alpha \times h_{\text {total }}} \times 100$

em que: $B$ é o volume da base consumida durante a hidrólise para manter o $\mathrm{pH}$ constante $(\mathrm{mL}) ; N_{b}$ é a normalidade da base; $M P$ é a massa de proteína (g, determinado $\mathrm{em} \mathrm{N} \times$ fator de Kjeldahl); $\alpha$ é o grau de dissociação; e $h_{\text {total }}$ é o número total de ligações peptídicas antes da reação.

Quando uma ligação peptídica é hidrolisada a pH superior a 6,5, o grupo carboxiterminal formado contribui para o abaixamento do $\mathrm{pH}$. O consumo de base (medido por titulação automática), necessário para manter o $\mathrm{pH}$ constante ao longo da reação, é utilizado no cálculo do $G H$. Considerando-se que o pK médio dos grupos amino seja constante, deverá existir uma proporcionalidade entre a liberação de prótons (igual ao consumo de base) e a quantidade de ligações peptídicas clivadas. O fator de proporcionalidade é o grau de dissociação dos grupos $\alpha$-amino $(\alpha)$, calculado através da Equação 2:

$$
\alpha=\frac{1}{1+10^{p K-p H}}
$$

em que: $\mathrm{pH}$ é constante e $\mathrm{pK}$ varia com a temperatura na qual a reação é conduzida.

O valor de pK, de acordo com Steinhart e Beychok (1964 apud KRISTINSSON; RASCO, 2000), pode ser estimado através da Equação 3:

$$
p K=7,8+\frac{298-T}{298 \times T} \times 2400
$$

em que: $T$ é a temperatura em Kelvin.

\subsection{Modelagem matemática da cinética de hidrólise enzimática}

O conhecimento da cinética de reações biotecnológicas é um parâmetro importante para projetar biorreatores e obter produtos com características desejadas. Entretanto, o estudo da cinética de hidrólise enzimática de proteínas é complicado, devido à existência de diferentes tipos de ligações peptídicas e à diferente acessibilidade dessas ao ataque enzimático (MÁRQUEZ; VÁZQUEZ, 1999; MORENO; CUADRADO, 1993).

Assim, há uma dificuldade em estabelecer modelos cinéticos para a hidrólise de macromoléculas. Se o modelo é muito simples, sua representação inadequada do mecanismo real limitará sua aplicabilidade, enquanto que um modelo complicado não pode ser analisado estatisticamente. Para contornar esses problemas, uma equação empírica simples da variação do grau de hidrólise pelo tempo (Equação 4) pode ser aplicada para expressar as curvas de hidrólise (MÁRQUEZ; VÁZQUEZ, 1999).

$\frac{d(G H)}{d t}=a \exp [-b \times G H]$

em que: $G H$ é o grau de hidrólise (\%); $t$ é o tempo (min); $a$ $\left(\min ^{-1}\right)$ e $b$ (adimensional) são parâmetros de cinética de hidrólise.

Essa equação de cinética considera uma reação de ordem zero com uma simultânea inativação da enzima de segunda ordem. Então, se a reação é

$$
E+S \longrightarrow E S \stackrel{k_{h}}{\longrightarrow} E+P
$$

então a taxa de reação será determinada pelo estágio irreversível (Equação 5):

$r=S_{0} \frac{d(G H)}{d t}=k_{h}|E S|$

em que: $E$ é a enzima; $S$ é o substrato; $E S$ é o complexo enzimasubstrato; $P$ é o produto; $r$ é a taxa de reação (g. $\left.\mathrm{L}^{-1} \cdot \mathrm{min}\right) ; S_{0}$ é a concentração inicial de substrato $\left(\mathrm{g} . \mathrm{L}^{-1}\right) ;|E S|$ é a concentração do complexo enzima-substrato; e $k_{\mathrm{h}}$ é a constante da hidrólise (g/AU.min).

Se a reação de inativação da enzima é

$$
E+E S \stackrel{k_{d}}{\longrightarrow} E+E_{i}+P
$$

então a equação da cinética para esse processo é dada pela seguinte Equação 6:

$-\frac{d e}{d t}=k_{d}|E||E S|$

em que: $E_{\mathrm{i}}$ é a enzima inativa; $e$ é a concentração de enzima (AU/l); e $k_{\mathrm{d}}$ é a constante da cinética de inativação da enzima (g/AU.min). 
A combinação dos processos de hidrólise enzimática e de inativação da enzima resulta na seguinte equação de taxa de hidrólise (Equação 7):

$$
r=k_{h} e_{0} \exp \left[-\frac{k_{d}}{k_{h}} G H\right]
$$

Substituindo-se a Equação 5 na Equação 7, tem-se a Equação 8.

$$
\frac{d(G H)}{d t}=\frac{k_{h} e_{0}}{S_{0}} \exp \left[-\frac{k_{d}}{k_{h}} G H\right]
$$

Comparando-se as Equações 4 e 8, obtém-se a relação entre os parâmetros $a$ e $b$ com as constantes de hidrólise e inativação de enzima (Equações 9 e 10):

$a=k_{h} \frac{e_{0}}{S_{0}}$

$b=\frac{k_{d}}{k_{h}}$

Integrando-se a Equação 5 e considerando-se a condição inicial $(t=0) \mathrm{GH}$ igual a zero, obtém-se uma equação de grau de hidrólise em função do tempo (Equação 11):

$G H=\frac{1}{b} \ln (1+a b t)$

\subsection{Planejamento experimental e análise estatística}

O planejamento experimental foi utilizado para estudar os efeitos das variáveis temperatura $T$, relação enzima:substrato E/S e pH sobre a cinética de hidrólise enzimática. Para isso, avaliaram-se os parâmetros $a$ e $b$, que relacionam as constantes da cinética de hidrólise e da cinética de inativação da enzima. Estes parâmetros foram obtidos através de um ajuste não linear da Equação 11 utilizando-se o software Statistica 5.0 (Statsoft, Tulsa, EUA). Os valores de temperatura, relação enzima: substrato e $\mathrm{pH}$ utilizados nos experimentos foram definidos através de ensaios preliminares.

O planejamento requer a execução de um número mínimo de experimentos. Neste estudo, foi realizado um planejamento fatorial completo $2^{3}$, com pontos centrais (nível 0) e pontos axiais (níveis $\pm \alpha$ ), totalizando 17 ensaios (Tabela 1), gerando um modelo quadrático, no qual o valor das variáveis dependentes $Y$ é função das variáveis independentes, conforme descreve a Equação 12.

$Y=\phi(T, E / S, p H)=\beta_{0}+\sum_{i=1}^{3} \beta_{i} X_{i}+\sum_{i=1}^{3} \beta_{i i} X_{i}^{2}+\sum_{i=1}^{2} \sum_{j=2}^{3} \beta_{i j} X_{i} X_{j}$

onde $\beta_{0}$ é a constante; $\beta_{\mathrm{I}}, \beta_{\mathrm{ii}}$ e $\beta_{\mathrm{ij}}$ são os coeficientes de regressão dos fatores lineares, quadráticos e das interações do modelo, respectivamente; e $X_{\mathrm{i}}$ e $X_{\mathrm{j}}$ representam as variáveis independentes em valores codificados.
Para a elaboração dos modelos, foi utilizado o software Statistica 5.0 (Statsoft, Tulsa, EUA), com a finalidade de assegurar a validade dos coeficientes dentro de um nível de confiança de $90 \%$, através de análises estatísticas apropriadas. Após a análise estatística dos coeficientes, foi realizada uma análise de variância (ANOVA), que consiste na avaliação do coeficiente de determinação $\left(\mathrm{R}^{2}\right)$ e do teste $F$, verificando-se se o modelo apresenta um ajuste adequado aos dados experimentais.

Para avaliar o ajuste da Equação 11 aos dados experimentais, foram utilizados o coeficiente de determinação entre as respostas observadas e os valores preditos pelo modelo e o módulo do desvio relativo médio $E$, cuja definição encontra-se descrita pela Equação 13:

$E=\frac{100}{N} \sum_{i=1}^{N} \frac{\left|V_{P}-V_{0}\right|}{V_{0}}$

em que: $E$ é o desvio relativo médio (\%); $V_{\mathrm{p}}$ são os valores preditos pelo modelo; $V_{0}$ são os valores observados experimentalmente; $N$ é o número de pontos experimentais.

\section{Resultados e discussão}

\subsection{Caracterização da matéria-prima}

A caracterização do peito de frango, obtida de acordo com AOAC (1997), é apresentada na Tabela 2.

\subsection{Cinética da hidrólise enzimática e modelagem matemática}

As curvas de cinética de hidrólise enzimática obtidas são mostradas nas Figuras 1a (ensaios fatorias), 1b (ensaios axiais) e 1c (ensaios centrais), nas quais se observa uma alta taxa inicial de reação, quando um grande número de ligações é quebrado, seguida pela diminuição da taxa até alcançar uma fase estacionária, em que aparentemente não ocorreu mais a reação. Curvas de hidrólise similares foram reportadas para resíduos de camarão, resíduos de atum, salmão, hemoglobina, soro de leite, resíduos de lagosta e capelim, respectivamente (HOLANDA; NETTO, 2006; GUERARD; GIMAS; BINET, 2002; KRISTINSSON; RASCO, 2000; MÁRQUEZ; VÁZQUEZ, 1999; CAMACHO; GONZÁLEZTELLO; GUADIX, 1998; BAEK; CADWALLADER, 1995; SHAHIDI; HAN; SYNOWIECKI, 1995).

Esse perfil da curva de hidrólise enzimática pode estar associado a diversos fatores, tais como: 1) diminuição da concentração de ligações peptídicas disponíveis para clivagem; 2) competição entre o substrato original e os peptídeos formados

Tabela 2. Composição centesimal da carne do peito de frango.

\begin{tabular}{cc}
\hline Conteúdo (bu, \%) & (Médio \pm desvio padrão) \\
\hline Umidade & $74,10 \pm 0,14$ \\
Proteínas & $19,36 \pm 0,94$ \\
Lipídios & $1,55 \pm 0,12$ \\
Cinzas & $1,10 \pm 0,01$ \\
\hline
\end{tabular}




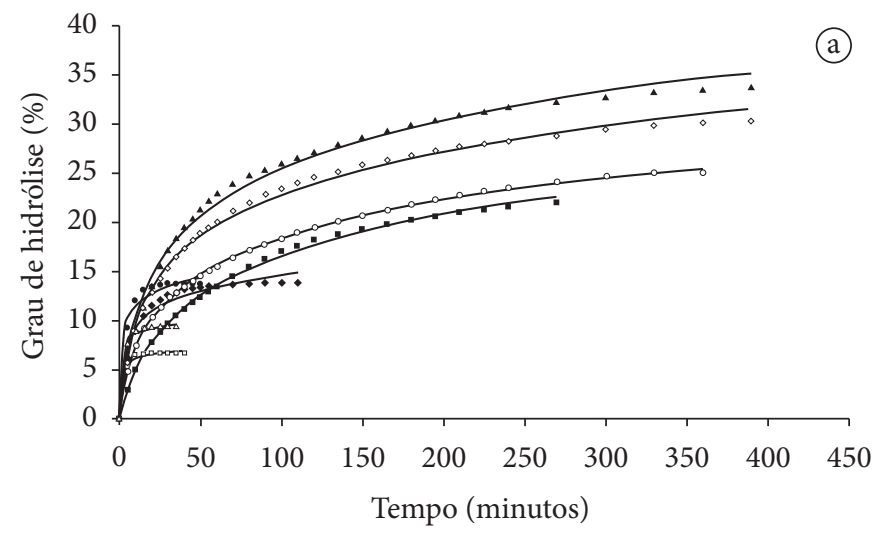

$50{ }^{\circ} \mathrm{C} / 1,5 \% / \mathrm{pH} 7,5 \quad \circ 50{ }^{\circ} \mathrm{C} / 1,5 \% / \mathrm{pH} 8,5$

- $70{ }^{\circ} \mathrm{C} / 1,5 \% / \mathrm{pH} 7,5$ - $70{ }^{\circ} \mathrm{C} / 1,5 \% / \mathrm{pH} 8,5$

- $50{ }^{\circ} \mathrm{C} / 3,5 \% / \mathrm{pH} 7,5$ - $50{ }^{\circ} \mathrm{C} / 3,5 \% / \mathrm{pH} 8,5$

- $70{ }^{\circ} \mathrm{C} / 3,5 \% / \mathrm{pH} 7,5$ - $70{ }^{\circ} \mathrm{C} / 3,5 \% / \mathrm{pH} 8,5$

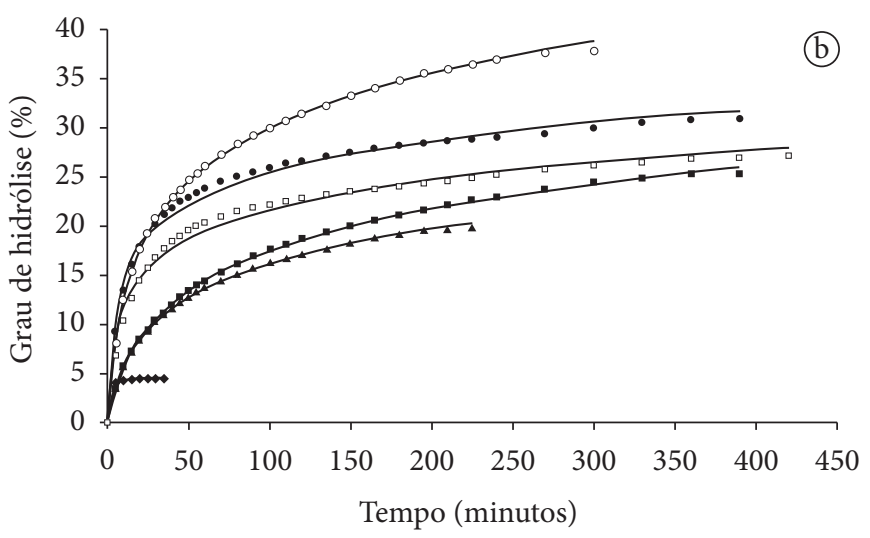

- $43{ }^{\circ} \mathrm{C} / 2,5 \% / \mathrm{pH} 8,0 \cdot 60^{\circ} \mathrm{C} / 4,2 \% / \mathrm{pH} 8,0$

- $77^{\circ} \mathrm{C} / 2,5 \% / \mathrm{pH} 8,0 \quad \circ 60^{\circ} \mathrm{C} / 2,5 \% / \mathrm{pH} 7,16$

- $60^{\circ} \mathrm{C} / 0,8 \% / \mathrm{pH} 8,0 \quad{ }^{\circ} 60^{\circ} \mathrm{C} / 2,5 \% / \mathrm{pH} 8,84$

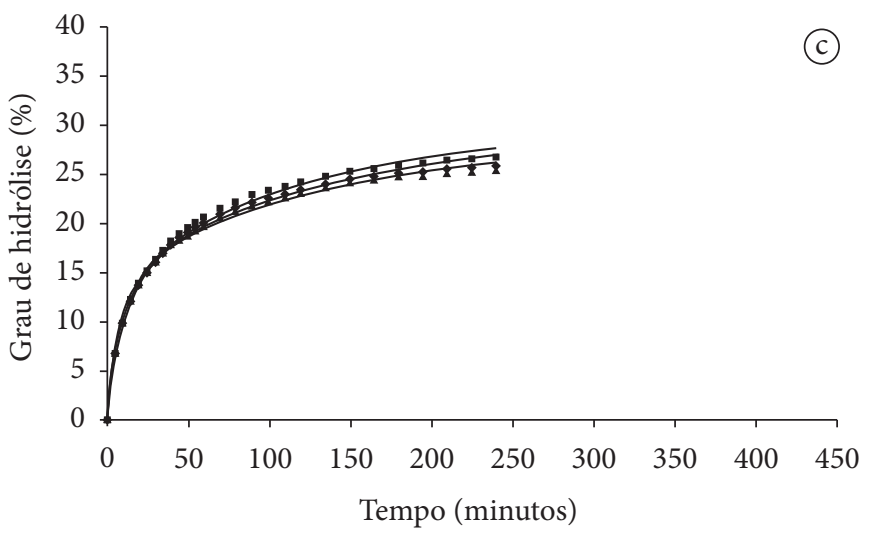

- $60^{\circ} \mathrm{C} / 2,5 \% / \mathrm{pH} 8,0$
- $60^{\circ} \mathrm{C} / 2,5 \% / \mathrm{pH} 8,0$
. $60^{\circ} \mathrm{C} / 2,5 \% / \mathrm{pH} 8,0$

Figura 1. Cinética de hidrólise enzimática de carne de frango e ajuste da equação de cinética aos dados experimentais de hidrólise enzimática de carne de frango, em que os pontos representam os dados observados e a curva, o modelo ajustado: a) Ensaio fatorias; b) Ensaios axiais; e c) Ensaios centrais. durante a reação; e 3) diminuição da atividade enzimática, devido à desnaturação da enzima (GUERARD; GIMAS; BINET, 2002; ADLER-NISSEN, 1985; GONZÁLEZ-TELLO et al., 1994).

Pela Figura 1a, observa-se que as curvas dos ensaios 2, 4, 6 e 8 apresentaram uma rápida clivagem das ligações peptídicas nos primeiros 15 minutos de reação, seguida da sua estabilização a um baixo grau de hidrólise. Isso pode ser explicado pela alta temperatura utilizada nesses ensaios $\left(70^{\circ} \mathrm{C}\right)$, que pode ter acarretado a desnaturação da enzima. $\mathrm{O}$ mesmo perfil pode ser verificado na Figura $1 \mathrm{~b}$ para o ensaio $10\left(77^{\circ} \mathrm{C}\right)$. Analisando-se os ensaios conduzidos a $50^{\circ} \mathrm{C}$ (Ensaios $1,3,5$ e 7$)$, verifica-se que os maiores valores de grau de hidrólise ocorreram a uma razão enzima:substrato de 3,5\% p/p (Ensaios 3 e 7).

A Figura $1 \mathrm{~b}$ mostra que os maiores valores de grau de hidrólise foram obtidos a maiores valores de temperatura $\left(60^{\circ} \mathrm{C}\right)$, com exceção do ensaio 11 , devido à baixa concentração de enzima utilizada $(0,8 \% \mathrm{p} / \mathrm{p})$. Observa-se que o ensaio 13 $\left(60^{\circ} \mathrm{C}, 2,5 \%\right.$ e pH 7,16$)$, mesmo com uma menor concentração de enzima usada em relação ao ensaio $12\left(60^{\circ} \mathrm{C}, 4,2 \%\right.$ e pH 8,0), apresentou maior valor de grau de hidrólise. Isso ocorre devido ao efeito do $\mathrm{pH}$ sobre a enzima, na qual a sua atividade catalítica é restrita a uma pequena faixa de $\mathrm{pH}$. Os pontos centrais, mostrados na Figura 1c, indicam a boa repetibilidade do processo.

A modelagem matemática foi realizada a fim de se predizer a cinética de hidrólise enzimática de carne de frango, utilizando a protease Alcalase. Para a obtenção dos parâmetros $a$ e $b$, foi realizada uma regressão não linear da equação de cinética (Equação 11) dos dados experimentais de grau de hidrólise e tempo de cada ensaio, usando como método de ajuste o modelo Quasi-Newton e o software Statistica (Statsoft, Tulsa, EUA). A Tabela 3 ilustra os parâmetros $a$ e $b$ obtidos, bem como os coeficientes de determinação $\mathrm{R}^{2}$ e os erros relativos médios $E$, calculados de acordo com a Equação 13, e as curvas do modelo ajustado estão mostrados na Figura 1.

Pela Tabela 3, nota-se que o modelo da cinética de hidrólise ajustou-se bem aos dados experimentais, com valores de $\mathrm{R}^{2}$ superiores a 0,96 e de erro relativo médio inferior a $10 \%$, valores aceitáveis para fins preditivos. Verifica-se que o parâmetro $a$ variou de $0,77-10,55$ e o parâmetro $b$ de $0,12-0,21$, com exceção dos ensaios $2,4,6,8$ e 10 , provavelmente devido às altas temperaturas, que acarretaram a desnaturação da enzima no início da reação, apresentando valores de $a$ muito mais altos que os observados nos demais experimentos.

\subsection{Planejamento experimental}

Para verificar a influência da temperatura $T$, da relação enzima: substrato $E / S$ e do $\mathrm{pH}$ sobre a cinética de hidrólise enzimática, os parâmetros $a$ e $b$, que relacionam as constantes da cinética de hidrólise e de inativação da enzima, foram avaliados. Entretanto, como pode ser observado na Tabela 3, houve uma grande variação dos parâmetros $a$ e $b$, com valores variando de 0,77 a 26914,4 e de 0,12 a 3,22, respectivamente. Assim, optou-se por converter as respostas $a$ e $b$ para escala logarítmica, de modo a obter melhores resultados no planejamento experimental. 
Tabela 3. Parâmetros de cinética obtidos dos ensaios de hidrólise enzimática de carne de frango.

\begin{tabular}{|c|c|c|c|c|c|c|c|}
\hline Ensaio & $\mathrm{T}\left({ }^{\circ} \mathrm{C}\right)$ & E/S (\%) & $\mathrm{pH}$ & $\mathrm{a}\left(\mathrm{min}^{-1}\right)$ & $\mathrm{b}$ & $\mathrm{R}^{2}$ & E (\%) \\
\hline 1 & 50 & 1,5 & 7,50 & 0,77 & 0,15 & 0,9981 & 1,4 \\
\hline 2 & 70 & 1,5 & 7,50 & 12,16 & 0,43 & 0,9646 & 5,3 \\
\hline 3 & 50 & 3,5 & 7,50 & 2,34 & 0,14 & 0,9926 & 3,6 \\
\hline 4 & 70 & 3,5 & 7,50 & 134,87 & 0,57 & 0,9794 & 4,2 \\
\hline 5 & 50 & 1,5 & 8,50 & 1,45 & 0,18 & 0,9989 & 1,3 \\
\hline 6 & 70 & 1,5 & 8,50 & 14930,92 & 2,03 & 0,9916 & 2,8 \\
\hline 9 & 43 & 2,5 & 8,00 & 0,90 & 0,15 & 0,9994 & 0,8 \\
\hline 10 & 77 & 2,5 & 8,00 & 26914,40 & 3,22 & 0,9989 & 1,1 \\
\hline 11 & 60 & 0,8 & 8,00 & 1,09 & 0,19 & 0,9993 & 0,9 \\
\hline 12 & 60 & 4,2 & 8,00 & 10,55 & 0,21 & 0,9889 & 3,0 \\
\hline 13 & 60 & 2,5 & 7,16 & 3,17 & 0,12 & 0,9991 & 0,9 \\
\hline 17 & 60 & 2,5 & 8,00 & 3,68 & 0,20 & 0,9938 & 2,5 \\
\hline
\end{tabular}

em que: T é a temperatura $\left({ }^{\circ} \mathrm{C}\right)$; E/S é a razão enzima:substrato (\%, p/p); $a$ e $b$ são os parâmetros da equação (11); $\mathrm{R}^{2}$ é o coeficiente de determinação; e E é o desvio relativo médio.

Os efeitos dos fatores lineares, quadráticos e das interações das respostas $\ln (a)$ e $\ln (b)$, assim como o erro, o coeficiente $\mathrm{t}$ e a significância estatística podem ser observados na Tabela 4 . Observa-se que os fatores temperatura linear e quadrático; $\mathrm{pH}$ linear e a interação $\mathrm{T} \times \mathrm{pH}$ foram significativos a $90 \%$ de confiança $(p \leq 0,1)$ para as respostas analisadas.

Através da Tabela 4, percebe-se que todos os parâmetros significativos a $\mathrm{p} \leq 0,10$ (temperatura $(\mathrm{L})$ e $(\mathrm{Q})$, razão enzima:substrato $(\mathrm{L}), \mathrm{pH}(\mathrm{L})$ e a interação temperatura $\times \mathrm{pH})$ apresentaram um efeito positivo na resposta $\ln (a)$, ou seja, um aumento em qualquer um desses fatores acarreta um aumento na resposta. Observa-se também que a média principal apresentou um p superior a 0,1 , não sendo considerado significativo. Entretanto, após a eliminação dos fatores não significativos, a média principal passou a ser significativa com a redução do seu valor de $\mathrm{p}$ (Tabela 5).

Analisando-se a resposta $\ln (b)$ na Tabela 5 , observa-se que os parâmetros significativos a $\mathrm{p}<0,1$ foram temperatura (L) e $(\mathrm{Q}), \mathrm{pH}(\mathrm{L})$ e a interação temperatura $\times \mathrm{pH}$ e que apresentaram um efeito positivo, sendo que o fator temperatura (L) foi o que apresentou maior efeito sobre a resposta analisada.

Eliminando-se os fatores não significativos, verificou-se a significância da regressão e da falta de ajuste a um nível de confiança de 95\%, através de uma Análise de Variância (ANOVA), utilizando-se o teste $F$ para o planejamento estudado. Na Tabela 6, encontram-se os valores calculados e tabelados de F.

O coeficiente de determinação para o modelo ajustado foi 0,9422 e 0,9702 para as respostas $\ln (a)$ e $\ln (b)$, respectivamente, indicando que os modelos obtidos explicaram 94,22 e 97,02\% da variação dos dados observados. De acordo com a Análise de Variância mostrada na Tabela 6, o modelo apresentou regressão significativa ao nível de $90 \%$ de confiança.
Tabela 4. Efeito estimado, erro padrão, coeficiente t e grau de significância estatística, para cada fator.

\begin{tabular}{|c|c|c|c|c|}
\hline \multicolumn{5}{|c|}{$\ln (\mathrm{a})$} \\
\hline Fatores & $\begin{array}{c}\text { Efeito } \\
\text { estimado }\end{array}$ & $\begin{array}{c}\text { Erro } \\
\text { padrão }\end{array}$ & $\mathrm{t}(7)$ & $\mathrm{p}$ - valor \\
\hline Média & 1,16 & 0,68 & 1,70 & 0,13 \\
\hline $\mathrm{T}(\mathrm{L})$ & 6,26 & 0,64 & 9,74 & $<0,01^{*}$ \\
\hline $\mathrm{T}(\mathrm{Q})$ & 3,13 & 0,71 & 4,43 & $<0,01^{\star}$ \\
\hline $\mathrm{E} / \mathrm{S}(\mathrm{L})$ & 1,21 & 0,64 & 1,89 & $0,10^{*}$ \\
\hline E/S (Q) & 0,42 & 0,71 & 0,59 & 0,57 \\
\hline $\mathrm{pH}(\mathrm{L})$ & 2,05 & 0,64 & 3,20 & $0,02^{*}$ \\
\hline $\mathrm{pH}(\mathrm{Q})$ & 0,60 & 0,71 & 0,85 & 0,42 \\
\hline $\mathrm{T} \times \mathrm{E} / \mathrm{S}$ & 0,34 & 0,84 & 0,41 & 0,70 \\
\hline $\mathrm{T} \times \mathrm{pH}$ & 2,93 & 0,84 & 3,50 & $0,01^{*}$ \\
\hline $\mathrm{E} / \mathrm{S} \times \mathrm{pH}$ & $-0,64$ & 0,84 & $-0,76$ & 0,47 \\
\hline \multicolumn{5}{|c|}{$\ln (\mathrm{b})$} \\
\hline Fatores & $\begin{array}{c}\text { Efeito } \\
\text { estimado }\end{array}$ & $\begin{array}{c}\text { Erro } \\
\text { padrão }\end{array}$ & $\mathrm{t}(7)$ & $\mathrm{p}$ - valor \\
\hline Média & $-1,68$ & 0,13 & $-12,79$ & $<0,01^{\star}$ \\
\hline $\mathrm{T}(\mathrm{L})$ & 1,79 & 0,12 & 14,54 & $<0,01^{\star}$ \\
\hline $\mathrm{T}(\mathrm{Q})$ & 1,04 & 0,14 & 7,63 & $<0,01^{\star}$ \\
\hline $\mathrm{E} / \mathrm{S}(\mathrm{L})$ & $-0,01$ & 0,12 & $-0,08$ & 0,94 \\
\hline E/S (Q) & 0,15 & 0,14 & 1,13 & 0,29 \\
\hline $\mathrm{pH}(\mathrm{L})$ & 0,57 & 0,12 & 4,63 & $<0,01^{\star}$ \\
\hline $\mathrm{pH}(\mathrm{Q})$ & 0,02 & 0,14 & 0,17 & 0,87 \\
\hline $\mathrm{T} \times \mathrm{E} / \mathrm{S}$ & 0,03 & 0,16 & 0,22 & 0,84 \\
\hline $\mathrm{T} \times \mathrm{pH}$ & 0,54 & 0,16 & 3,38 & $0,01^{*}$ \\
\hline $\mathrm{E} / \mathrm{S} \times \mathrm{pH}$ & $-0,17$ & 0,16 & $-1,02$ & 0,34 \\
\hline
\end{tabular}

(L): linear; (Q): quadrático; $\mathrm{e}^{\star}$ significante a $\mathrm{p}<0,10$.

Sendo assim, os modelos decodificados (Equações 14 e 15) ajustados para as respostas $\ln (a)$ e $\ln (b)$ são os seguintes:

$\ln (a)=1,66+3,13 \times T+1,45 \times T^{2}+0,61 \times E / S+$ 
$a=\exp \left(1,66+3,13 \times T+1,45 \times T^{2}+0,61 \times E / S+\right.$

$1,03 \times p H+1,48 \times T \times p H)$

$\ln (b)=-1,59+0,90 \times T+0,50 \times T^{2}+$

$0,28 \times p H+0,27 \times T \times p H$

$b=\exp \left(-1,59+0,90 \times T+0,50 \times T^{2}+\right.$

$0,28 \times p H+0,27 \times T \times p H)$

em que: $T$ é a temperatura e $E / S$ é a relação enzima:substrato.

A superfície de resposta e a curva de nível, geradas através dos modelos propostos, estão mostradas nas Figuras 2 e 3, que expressam a interação entre duas variáveis independentes sobre a resposta. Neste caso, a terceira variável foi mantida no ponto central do planejamento.

Tabela 5. Efeito estimado, erro padrão, coeficiente t e grau de significância estatística, para cada fator após a eliminação dos fatores não significativos a $\mathrm{p}<0,05$.

\begin{tabular}{lcccc}
\hline \multicolumn{5}{c}{$\ln (\mathrm{a})$} \\
\hline Fatores & $\begin{array}{c}\text { Efeito } \\
\text { estimado }\end{array}$ & $\begin{array}{c}\text { Erro } \\
\text { padrão }\end{array}$ & $\mathrm{t}(7)$ & $\mathrm{p}$ - valor \\
\hline Média & 1,66 & 0,35 & 4,82 & $<0,01$ \\
$\mathrm{~T}(\mathrm{~L})$ & 6,26 & 0,57 & 11,02 & $<0,01$ \\
$\mathrm{~T}(\mathrm{Q})$ & 2,90 & 0,58 & 4,98 & $<0,01$ \\
$\mathrm{E} / \mathrm{S}(\mathrm{L})$ & 1,21 & 0,57 & 2,14 & 0,06 \\
$\mathrm{pH}(\mathrm{L})$ & 2,05 & 0,57 & 3,61 & $<0,01$ \\
$\mathrm{~T} \times \mathrm{pH}$ & 2,93 & 0,74 & 3,96 & $<0,01$ \\
\hline & & $\ln (\mathrm{b})$ & & $\mathrm{p}-$ valor \\
\hline Fatores & Efeito & Erro & $\mathrm{t}(7)$ & $<0,01$ \\
& estimado & padrão & & $<0,01$ \\
Média & $-1,59$ & 0,07 & $-23,93$ & $<0,01$ \\
$\mathrm{~T}(\mathrm{~L})$ & 1,79 & 0,11 & 16,41 & $<0,01$ \\
$\mathrm{~T}(\mathrm{Q})$ & 1,00 & 0,11 & 8,90 & $<0,01$ \\
$\mathrm{pH}(\mathrm{L})$ & 0,57 & 0,11 & 5,23 & 3,81 \\
$\mathrm{~T} \times \mathrm{pH}$ & 0,54 & 0,14 & &
\end{tabular}

(L): linear; (Q): quadrático.

Tabela 6. Análise de variância do modelo ajustado para as respostas $\ln (a)$ e $\ln (\mathrm{b})$.

\begin{tabular}{|c|c|c|c|c|c|}
\hline \multicolumn{6}{|c|}{$\ln (\mathrm{a})$} \\
\hline Fonte de variação & SQ & GL & MQ & $\mathrm{F}_{\text {calculado }}$ & $\mathrm{F}_{\text {tabelado }} *$ \\
\hline Regressão & 197,41 & 5 & 39,48 & 35,89 & 2,45 \\
\hline Resíduo: & 12,10 & 11 & 1,10 & & \\
\hline - Falta de ajuste & 12,09 & 9 & 1,34 & 274,48 & 9,38 \\
\hline - Erro puro & 0,01 & 2 & $<0,01$ & & \\
\hline Total & 209,51 & 16 & & & \\
\hline \multicolumn{6}{|c|}{$\ln (\mathrm{b})$} \\
\hline Fonte de variação & SQ & GL & MQ & $\mathrm{F}_{\text {calculado }}$ & $\mathrm{F}_{\text {tabelado }} *$ \\
\hline Regressão & 15,92 & 4 & 3,98 & 97,61 & 2,48 \\
\hline Resíduo: & 0,49 & 12 & 0,04 & & \\
\hline - Falta de ajuste & 0,48 & 10 & 0,05 & 17,43 & 9,39 \\
\hline - Erro puro & 0,01 & 2 & $<0,01$ & & \\
\hline Total & 16,41 & 16 & & & \\
\hline
\end{tabular}

SQ: Soma quadrática; GL: grau de liberdade; MQ: média quadrática; $\mathrm{e}^{*}$ valor tabelado de $\mathrm{F}$ a $\mathrm{p}<0,10$. 
Analisando-se as Figuras $2 \mathrm{~b}$ e $3 \mathrm{~b}$, observa-se o efeito da interação $\mathrm{T} \times \mathrm{pH}$, em que, para temperaturas inferiores a $50{ }^{\circ} \mathrm{C}$, aproximadamente, há uma diminuição das respostas com o aumento do $\mathrm{pH}$, enquanto que para temperaturas acima deste valor, observa-se um comportamento inverso, com um aumento das respostas com o pH. Já as Figuras $2 \mathrm{c}$ e $3 \mathrm{c}$ indicam um efeito linear positivo do $\mathrm{pH}$ sobre os parâmetros cinéticos. $\mathrm{O} \mathrm{pH}$ é uma variável importante em uma reação enzimática. De acordo
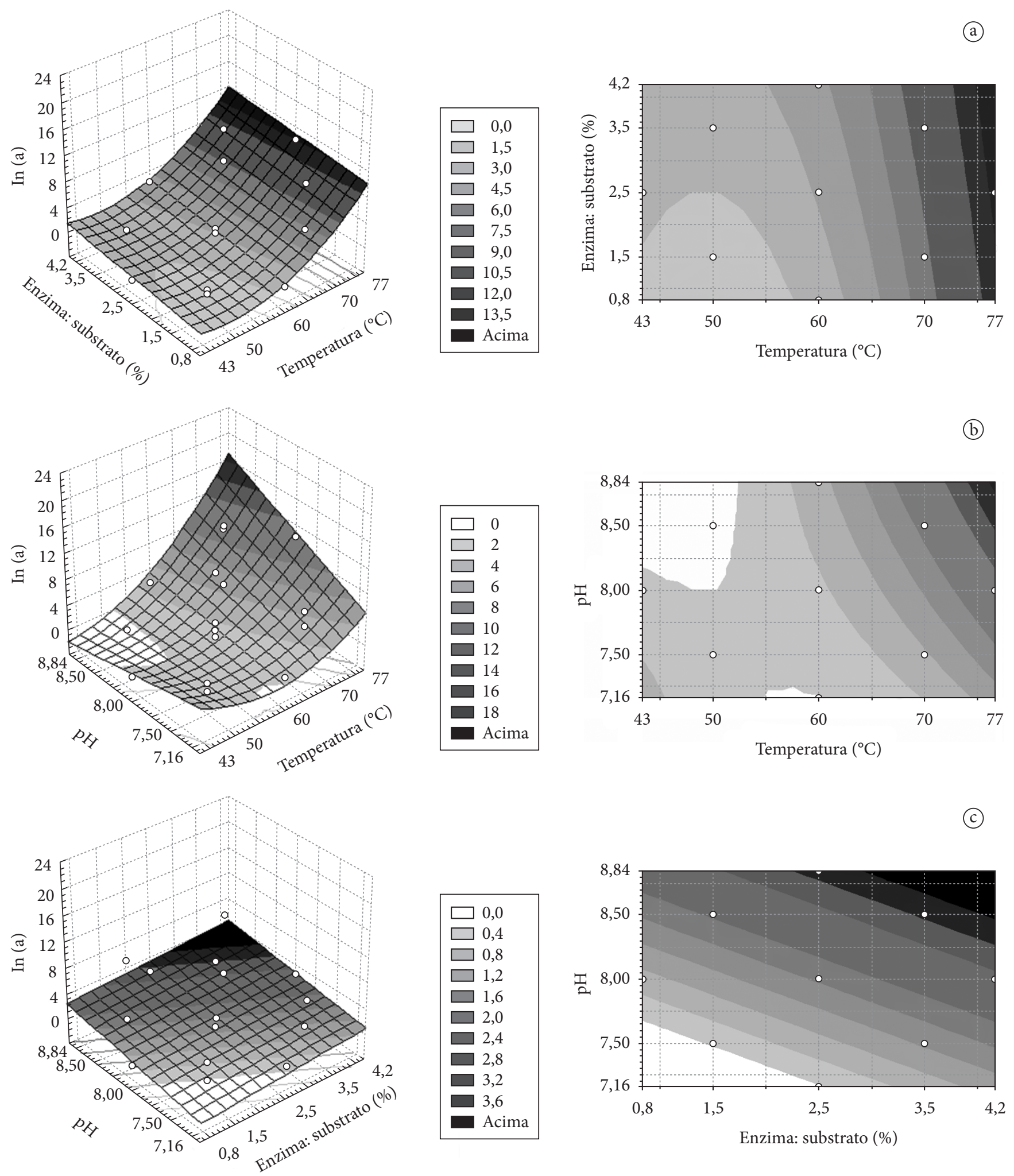

Figura 2. Influência das variáveis independentes sobre a resposta $\ln (\mathrm{a})$. 

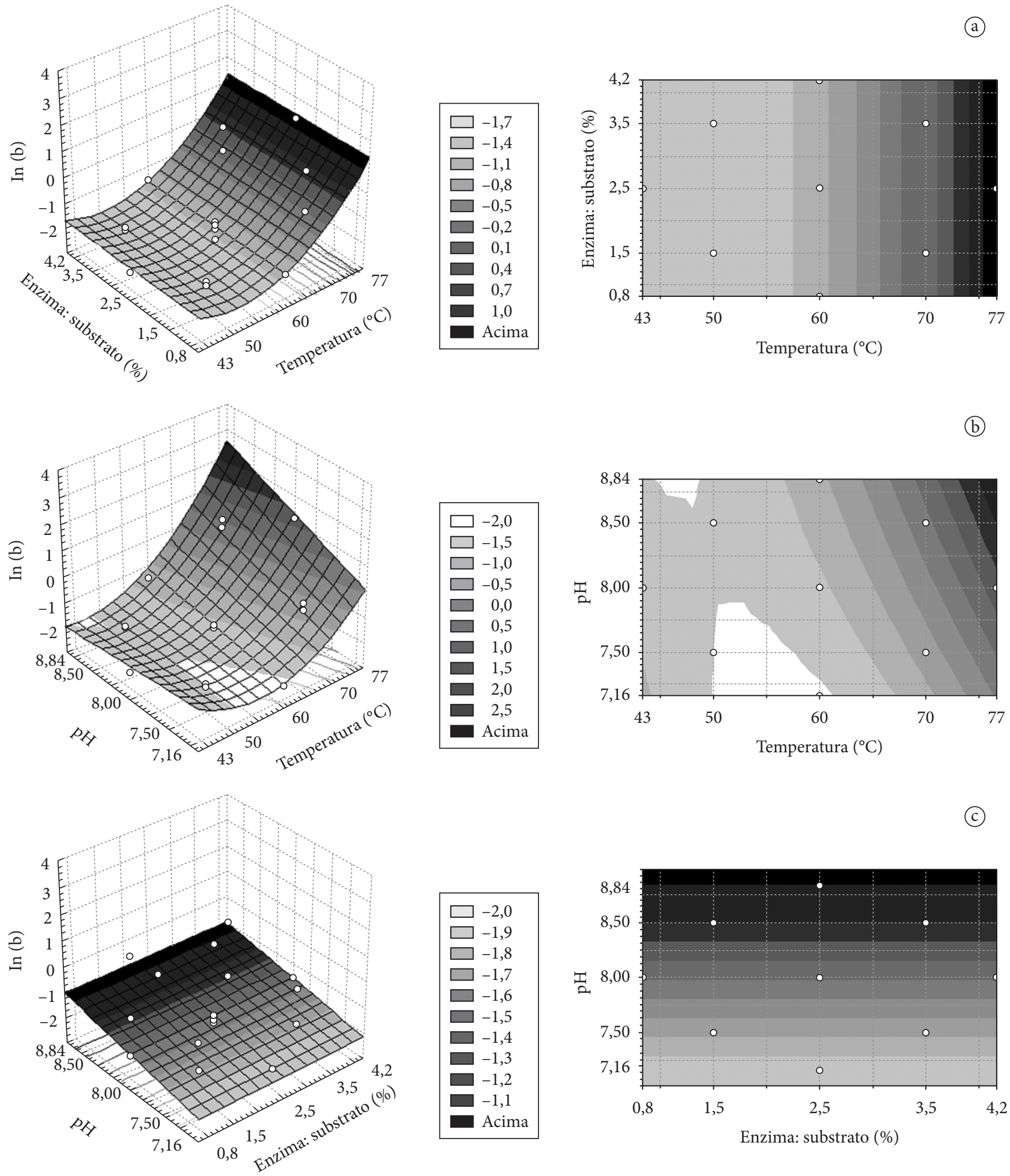

Figura 3. Influência das variáveis independentes sobre a resposta $\ln (\mathrm{b})$.

com Whitaker (1994), uma mudança do pH em uma reação enzimática pode afetar a estabilidade da enzima, causando uma desnaturação irreversível em sua estrutura conformacional, resultando em uma contínua perda da sua atividade. Embora a enzima Alcalase geralmente apresente uma alta estabilidade em uma ampla faixa de $\mathrm{pH}$, sua redução pode ocorrer quando o tempo de processo é muito longo, uma vez que a estabilidade da enzima é dependente do tempo (DINIZ; MARTIN, 1998). 


\section{Conclusões}

As curvas da cinética de reação enzimática obtidas foram similares às reportadas na literatura, apresentando uma alta taxa inicial de reação, seguidas da sua diminuição até alcançar uma fase estacionária. Observou-se a influência das variáveis estudadas na hidrólise enzimática. A equação da cinética enzimática de proteína mostrou-se adequada para modelar a reação enzimática de carne de frango, apresentando um bom ajuste aos dados experimentais. Os parâmetros obtidos deste modelo foram avaliados através de um planejamento experimental. Através da Metodologia de Superfície de Resposta, foi possível analisar o comportamento dos parâmetros cinéticos com as variáveis temperatura, razão enzima:substrato e $\mathrm{pH}$. A temperatura foi a variável com maior efeito sobre a reação enzimática, na qual se observa um aumento dos parâmetros com a temperatura. A variável razão enzima:susbtrato não afetou o parâmetro $b$ e teve efeito positivo sobre o parâmetro $a$. A variável $\mathrm{pH}$ afetou significantemente as respostas estudadas.

\section{Agradecimentos}

Os autores agradecem à Universidade Estadual de Campinas (UNICAMP), à Coordenação de Aperfeiçoamento de Pessoal de Nível Superior (Capes), ao Conselho Nacional de Desenvolvimento Científico e Tecnológico (CNPq) e à Fundação de Amparo à Pesquisa do Estado de São Paulo (Fapesp) pelo suporte financeiro.

\section{Referências bibliográficas}

ADLER-NISSEN, J. Enzymic hydrolysis of food protein. London: Elsevier Applied Science Publishers, 1985.

BAEK, H. H.; CADWALLADER, K. R. Enzymatic hydrolysis of crayfish processing by-products. Journal of Food Science, v. 60, n. 5, p. 929-935, 1995.

BARROS NETO, B.; SCARMINIO, I. S.; BRUNS, R. E. Planejamento e otimização de experimentos. 2 ed. Campinas: Editora da UNICAMP, 1996.

BHASKAR, N. et al. Optimization of enzymatic hydrolysis of visceral waste proteins of catla (Catla catla) for preparing protein hydrolysate using a commercial protease. Bioresource Technology, 2007a. In press.

BHASKAR, N. et al. Utilization of meat industry by products: protein hydrolysate from sheep visceral mass. Bioresource Technology, v. 98 , n. 2, p. 388-394, 2007 b.

CAMACHO, F.; GONZÁLEZ-TELLO, P.; GUADIX, E. M. Influence of enzymes, $\mathrm{pH}$ and temperature on the kinetics of whey protein hydrolysis. Food Science and Technology International, v. 4, n. 2 , p. 79-84, 1998.

DINIZ, F. M.; MARTIN, A. M. Optimization of nitrogen recovery in the enzymatic hydrolysis of dogfish (Squalus acanthias) protein. Composition of the hydrolysate. International Journal of Food Sciences and Nutrition, v. 48, n. 3, p. 191-200, 1997.

DINIZ, F. M.; MARTIN, A. M. Influence of process variables on the hydrolysis of shark muscle protein. Food Science and Technology, v. 4, n. 2, p. 91-98, 1998.

FELÍCIO, P. E. de. Valor nutritivo da carne. Disponível em: $<$ http://www. sic.org.br/PDF/Valornutritivo.pdf>. Acesso em: 19 Maio 2006.

FURLAN, E. F; OETTERER, M. Hidrolisado protéico de pescado. Ciência e Tecnologia, v. 10, n. 19, p. 79-89, 2002.
GONZÁLEZ-TELLO, P. et al. Enzymatic hydrolysis of whey proteins: I. Kinetic Models. Biotechnology and Bioengineering, v. 44, n. 4, p. 523-528, 1994.

GUERARD, F.; GUIMAS, L.; BINET, A. Production of tuna waste hydrolysates by a commercial neutral protease preparation. Journal of Molecular Catalysis B: Enzymatic, v. 19-20, p. 489-498, 2002.

HOLANDA, H. D. de; NETTO, F. M. Recovery of components from shrimp (Xiphopenaeus kroyeri) processing waste by enzymatic hydrolysis. Journal of Food Science, v. 71, n. 5, p. 298-303, 2006.

KRISTINSSON, H. G.; RASCO, B. A. Kinetics of the hydrolysis of atlantic salmon (Salmo salar) muscle proteins by alkaline proteases and a visceral serine protease mixture. Process Biochemistry, v. 36, n. 9, p.131-139, 2000.

MÁRQUEZ, M. C.; VÁZQUEZ, M. A. Modeling of enzymatic protein hydrolysis. Process Biochemistry, v. 35, n. 1, p. 111-117, 1999.

MARTINS, M. T. S. Caracterização química e nutricional de plasteína produzida a partir de hidrolisado pancreático de isolado protéico de soja. Ciência e Tecnologia de Alimentos, v. 25, n. 4, p. 683-690, 2005.

MATIAS, A. B.; MEIRELLES, J. L. F.; CALDEIRA, L. M. Estratégia, investimento e competitividade da indústria avícola brasileira. Disponível em: <http://www.cepefin.com.br/publicados_pdf/ estrategia_investimento_e_competitividade_da_industria_avicola_ brasileira_semead_2003.pdf>. Acesso em: 23 Maio 2006.

MORENO, M. C. M.; CUADRADO, V. F. Enzymic hydrolysis of vegetables proteins: mechanism and kinetics. Process Biochemistry, v. 28, n. 7, p. 481-490, 1993.

NILSANG, S. et al. Optimization of enzymatic hydrolysis of fish soluble concentrate by commercial proteases. Journal of Food Engineering, v. 70, n. 4, p. 571-578, 2005.

RODRIGUES, M. I.; IEMMA, A. F. Planejamento de experimentos e otimização de processos. Campinas: Casa do Pão Editora, 2005.

ROMAN, J. A.; SGARBIERI, V. C. Efeito da hidrólise enzimática sobre propriedades funcionais de caseína bovina coagulada pela ação da quimosina. Ciência e Tecnologia de Alimentos, v. 25, n. 3, p. 468-474, 2005.

SATHIVEL, S. et al. Functional and nutritional properties of red salmon (Oncorhynchus nerka) enzymatic hydrolysates. Journal of Food Science, v. 70, n. 6, p. 401-406, 2005.

SGARBIERI, V. C. Proteínas em alimentos protéicos: Propriedades degradações - modificações. São Paulo: Varela, 1996.

SHAHIDI, F.; HAN, X. Q.; SYNOWIECKI, J. Production and characteristics of protein hydrolysates from capelin (Mallotus villosus). Food Chemistry, v. 53, n. 3, p. 285-293, 1995.

TACO. Tabela brasileira de composição de alimentos. Campinas: NEPA-UNICAMP, 2004.

WASSWA, J. et al. Influence of the extent of enzymatic hydrolysis on the functional properties of protein hydrolysate from grass carp (Ctenopharyngodon idella) skin. Food Chemistry, v. 104, n. 4, p. 1698-1704, 2007.

WHITAKER, J. R. Principles of enzymology for the food sciences. 2 ed. New York, Basel \& Hong Kong: Marcel Dekker, 1994.

XIA, S. H.; WANG, Z.; XU, S. Y. Characteristics of Bellamya purificata snail foot protein and enzymatic hydrolysates. Food Chemistry, v. 101, n. 3, p. 1188-1196, 2007. 